\title{
The Fate of Spacers in the Treatment of Periprosthetic Joint Infection.
}

\author{
Miguel M Gomez \\ Rothman Institute at Thomas Jefferson University \\ Timothy L Tan \\ Rothman Institute at Thomas Jefferson University \\ Jorge Manrique \\ Rothman Institute at Thomas Jefferson University \\ Gregory K Deirmengian \\ Rothman Institute at Thomas Jefferson University \\ Javad Parvizi MD \\ Rothman Institute at Thomas Jefferson Univerșity \\ Follow this and additional works at: https://jdc.jefferson.edu/rothman_institute \\ Part of the Orthopedics Commons \\ Let us know how access to this document benefits you
}

\section{Recommended Citation}

Gomez, Miguel M; Tan, Timothy L; Manrique, Jorge; Deirmengian, Gregory K; and Parvizi, Javad MD, "The Fate of Spacers in the Treatment of Periprosthetic Joint Infection." (2015). Rothman Institute Faculty Papers. Paper 66.

https://jdc.jefferson.edu/rothman_institute/66

This Article is brought to you for free and open access by the Jefferson Digital Commons. The Jefferson Digital Commons is a service of Thomas Jefferson University's Center for Teaching and Learning (CTL). The Commons is a showcase for Jefferson books and journals, peer-reviewed scholarly publications, unique historical collections from the University archives, and teaching tools. The Jefferson Digital Commons allows researchers and interested readers anywhere in the world to learn about and keep up to date with Jefferson scholarship. This article has been accepted for inclusion in Rothman Institute Faculty Papers by an authorized administrator of the Jefferson Digital Commons. For more information, please contact: JeffersonDigitalCommons@jefferson.edu. 


\section{The Fate of Spacers in the Treatment of Periprosthetic Joint Infection}

Miguel M. Gomez, MD, Timothy L. Tan, MD, Jorge Manrique, MD, Gregory K. Deirmengian, MD, and Javad Parvizi, MD, FRCS

Investigation performed at the Rothman Institute at Thomas Jefferson University, Philadelphia, Pennsylvania

Background: Two-stage exchange arthroplasty remains the preferred method to treat periprosthetic joint infection. The aim of this study was to investigate the clinical course of periprosthetic joint infection following resection arthroplasty and insertion of a spacer.

Methods: Our institutional database was used to identify 504 cases of periprosthetic joint infection ( 326 knees and 178 hips) treated with resection arthroplasty and spacer insertion as part of a two-stage exchange arthroplasty. A review of the patient charts was performed to extract information relevant to the objectives of this study that included the details of the clinical course following resection arthroplasty.

Results: The mean follow-up duration after initial spacer implantation was 56.2 months. Reimplantation occurred in the joints of 417 (82.7\%) of 504 cases. Of these 417 cases, 329 (78.9\%) had a minimum one-year follow-up, and $81.4 \%$ of these had successful treatment. The mean duration from resection arthroplasty to reimplantation was 4.2 months (range, 0.7 to 131.7 months). Sixty (11.9\%) of the 504 joints required interim spacer exchange(s). Of the eighty-seven cases that did not undergo reimplantation, six (6.9\%) required amputation, five $(5.7 \%)$ underwent a Girdlestone procedure, four (4.6\%) underwent arthrodesis, and seventy-two (82.8\%) underwent spacer retention. Thirty-six patients died in the interstage period.

Conclusions: The commonly held belief that two-stage exchange arthroplasty carries a high success rate for the eradication of periprosthetic joint infection may need to be reexamined. A considerable number of patients undergoing the first stage of a two-stage procedure do not undergo a subsequent reimplantation for a variety of reasons or require an additional spacer exchange in the interim. Reports on the success of two-stage exchange should account for the mortality of these patients and for patients who never undergo reimplantation.

Level of Evidence: Therapeutic Level IV. See Instructions for Authors for a complete description of levels of evidence.

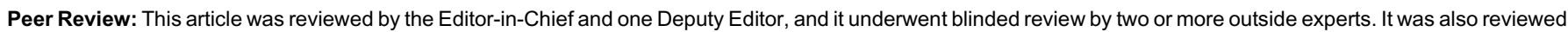

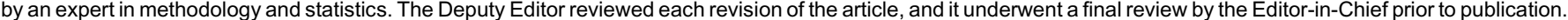
Final corrections and clarifications occurred during one or more exchanges between the author(s) and copyeditors.

$\mathrm{T}$ 1 he treatment of periprosthetic joint infection continues to pose challenges for the orthopaedic community ${ }^{1}$. The preferred surgical treatment of chronic periprosthetic joint infection in North America is two-stage exchange arthroplasty that involves removal of the prosthesis and spacer placement, followed by reimplantation of new components during the second stage.
The reported success of two-stage exchange arthroplasty has varied in the literature, with some studies showing a 100\% rate for infection control ${ }^{2-5}$. However, the majority of those studies focused on the clinical outcomes following successful reimplantation and thus may not accurately reflect the overall success rate of two-stage exchange for periprosthetic joint

Disclosure: None of the authors received payments or services, either directly or indirectly (i.e., via his or her institution), from a third party in support of any aspect of this work. One or more of the authors, or his or her institution, has had a financial relationship, in the thirty-six months prior to submission of this work, with an entity in the biomedical arena that could be perceived to influence or have the potential to influence what is written in this work. No author has had any other relationships, or has engaged in any other activities, that could be perceived to influence or have the potential to influence what is written in this work. The complete Disclosures of Potential Conflicts of Interest submitted by authors are always provided with the online version of the article. 
The Journal of Bone \& Joint Surgery $\cdot$ Jbjs.org Volume 97-A · Number $18 \cdot$ September 16,2015

The Fate of Spacers in the Treatment of Periprosthetic JOINT INFECTION

TABLE I Patient Demographic Characteristics

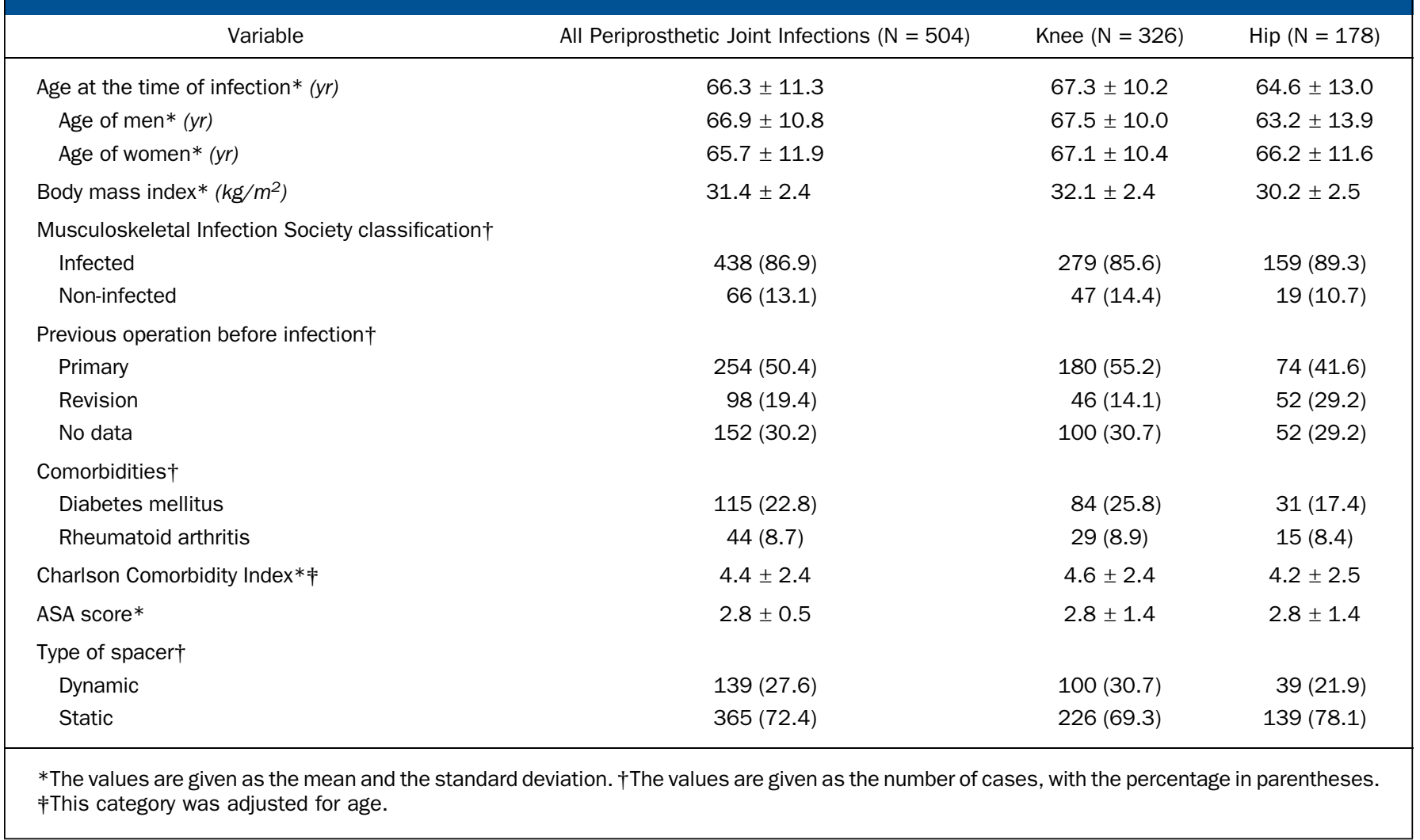

infection. Furthermore, there is considerable variability in the literature with regard to how these studies define the success of periprosthetic joint infection treatment, which could result in an overestimation of the outcome measures. In addition, the study populations often consist of a small cohort ${ }^{6}$.

To accurately depict the clinical course of two-stage exchange, an enhanced understanding of the interstage period is needed. Although there are many studies that investigated the role of spacer selection (static or dynamic) in either functional outcomes or infection control ${ }^{7-11}$, very few, if any, to our knowledge, have investigated the clinical course following the first stage of a two-stage exchange arthroplasty. Furthermore, little is known with regard to the fate of spacers in these patients undergoing a two-stage exchange arthroplasty.

The aim of this study was to investigate the natural history of resection arthroplasty and spacer implantation in patients undergoing the first stage of a planned two-stage exchange arthroplasty for treatment of periprosthetic joint infection.

\section{Materials and Methods \\ Patient Demographic Characteristics}

Collowing institutional review board approval, our institutional joint arFthroplasty database was queried to identify 647 periprosthetic joint infections in patients who underwent resection arthroplasty and spacer insertion as part of an intended two-stage exchange arthroplasty for suspected periprosthetic joint infection. The period of study was from 1999 to 2013 and, during this time, 32,417 patients had undergone joint arthroplasty at our institution. Patients with a megaprosthesis, prior native septic arthritis, prior two-stage exchange, or failed one-stage exchange, or those who underwent spacer placement for reasons unrelated to periprosthetic joint infection were excluded. After exclusion of 143 cases on the basis of the above criteria, a total of 504 periprosthetic joint infections ( 326 knees and 178 hips) in 482 patients were included in the final cohort (Table I).

\section{Component Specifications}

At the time of initial spacer implantation, 365 periprosthetic joint infections (72.4\%) were treated with nonarticulating spacers and 139 periprosthetic joint infections (27.6\%) were treated with articulating spacers. The articulating spacers were intraoperatively constructed primarily from prefabricated molds with endoskeleton implants (StageOne; Biomet, Warsaw, Indiana). The use of articulating spacers increased during the study period from $0.0 \%$ in 1999 to $26.9 \%$ in 2013 . Dual antibiotics were in $97.6 \%$ of spacers, consisting almost entirely of 1 to $4 \mathrm{~g}$ per pack (range of total grams, 1 to $12 \mathrm{~g}$ ), to ensure activity against gram-positive and gram-negative organisms; vancomycin was in $99.1 \%$ of spacers and tobramycin was in $96.4 \%$ of spacers. In $2.4 \%$ of cases, the antibiotic utilized was an antifungal or cephalosporin, which was based on the suspected organism or used if an allergy to the standard antibiotic was present. The dosages increased during the time course of the study, with the recent spacers regularly using $3 \mathrm{~g}$ of vancomycin and 2.4 to $3 \mathrm{~g}$ of tobramycin. Reimplantation was scheduled to occur following a minimum of four weeks, but the duration of the interstage period was not otherwise designated. The timing of reimplantation was based on laboratory values and clinical improvements. The erythrocyte sedimentation rate and C-reactive protein values were examined for progressive sequential decreases. Prior to reimplantation, aspiration was not routinely performed. In addition, clinical signs and improvement were monitored as a proxy for infection control, particularly during the antibiotic-free period. At the time of reimplantation, spacers were removed and repeat debridement was performed, followed by insertion of routine revision-type prosthetic components utilizing antibiotic-loaded cement in total knee arthroplasties and uncemented total hip arthroplasties. When cemented components were used in the hip, antibiotic-loaded bone cement was utilized. 
The Journal of Bone \& Joint Surgery $\cdot$ JBjS. Org Volume 97-A · Number $18 \cdot$ September 16,2015
The Fate of Spacers in the Treatment of Periprosthetic JOINT INFECTION

\section{TABLE II Outcomes and Complications Following Initial Spacer Implantation}

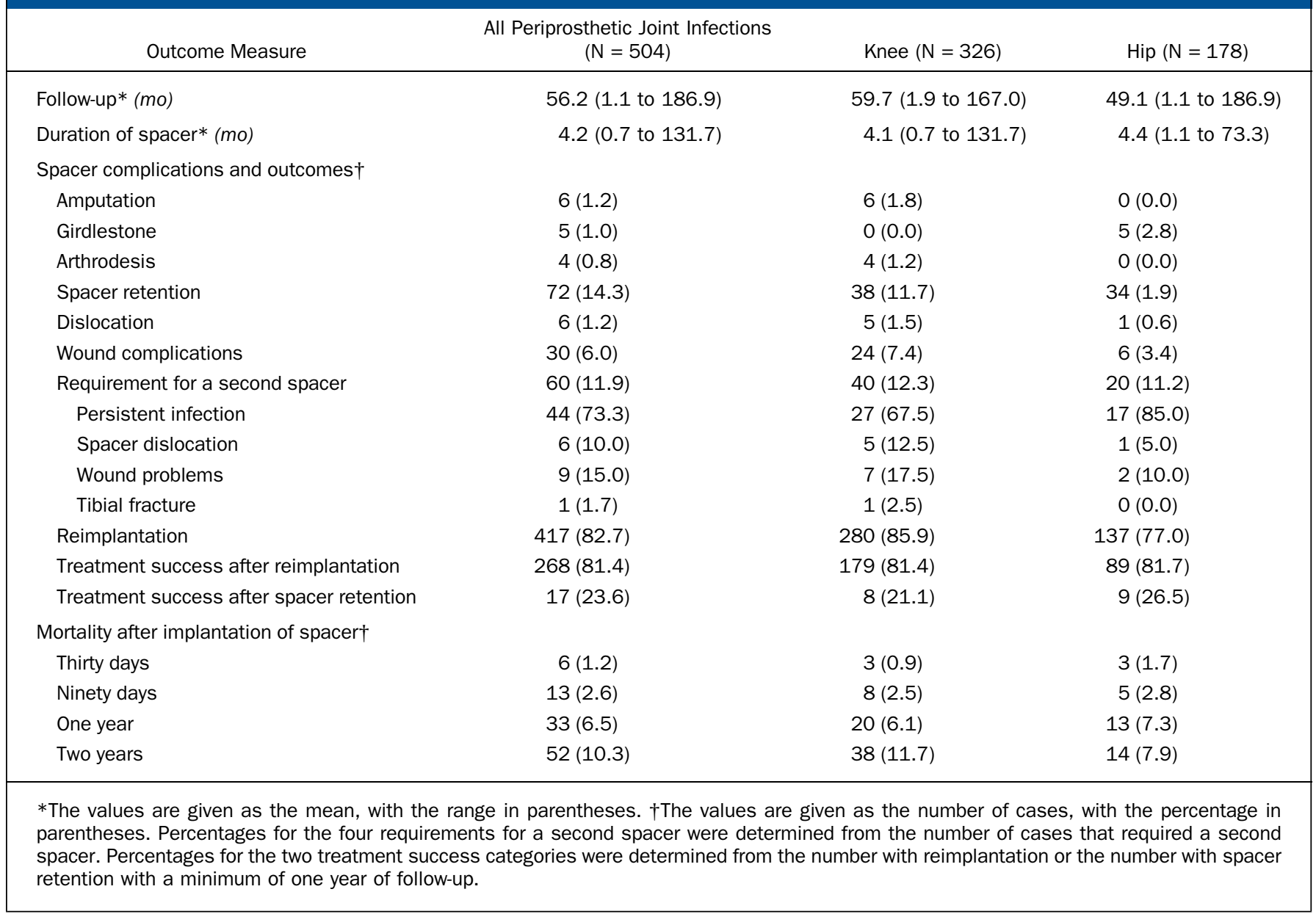

TABLE III Organism Profile at Initial Spacer Implantation*

\begin{tabular}{|c|c|c|c|}
\hline Microorganism & $\begin{array}{l}\text { All Periprosthetic Joint } \\
\text { Infections }(N=504)\end{array}$ & Knee $(\mathrm{N}=326)$ & $\operatorname{Hip}(\mathrm{N}=178)$ \\
\hline Coagulase-negative Staphylococcus & $84(16.7)$ & $60(18.4)$ & $24(13.5)$ \\
\hline Streptococcus species & $36(7.1)$ & $27(8.3)$ & $9(5.1)$ \\
\hline Enterococcus species & $9(1.8)$ & $5(1.5)$ & $4(2.2)$ \\
\hline Other organism & $19(3.8)$ & $16(4.9)$ & $3(1.7)$ \\
\hline Polymicrobial & $39(7.7)$ & $24(7.4)$ & $15(8.4)$ \\
\hline Negative cultures & $136(27.0)$ & $91(27.9)$ & $45(25.3)$ \\
\hline
\end{tabular}


The Journal of Bone \& Joint Surgery $\cdot$ Jbjs.org Volume 97-A • Number $18 \cdot$ September 16, 2015

The Fate of Spacers in the Treatment of Periprosthetic JOINT INFECTION

TABLE IV Reimplantation Rate by Organism and Comorbidity*

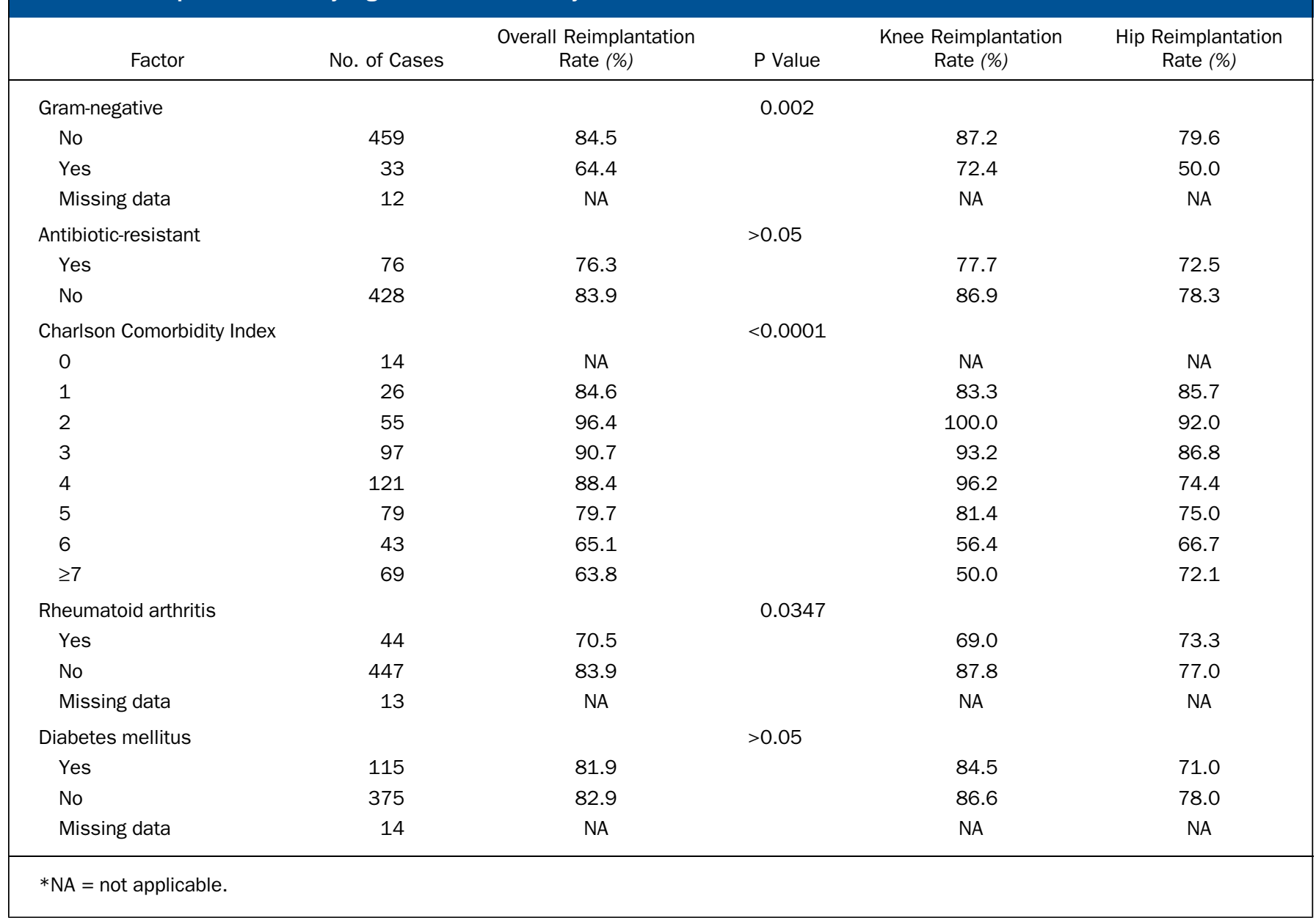

\section{Outcome Variables}

A retrospective chart review was performed to extract patient demographic characteristics and all of the relevant data, which included the following variables: surgical procedure details and the type of spacer placed, microbiological data related to the infecting organism(s), and the clinical course of the patients after resection arthroplasty and spacer placement. Details pertinent to subsequent operations, including the reimplantation, were also extracted.

From the institutional database, queries were performed to obtain information on patient comorbidities including body mass index, diabetes mellitus, rheumatoid arthritis, Charlson Comorbidity Index, and American Society of Anesthesiologists (ASA) classification ${ }^{12}$. The Charlson Comorbidity Index provides a method of quantifying overall health and is predictive of mortality ${ }^{13}$. Data related to mortality were ascertained from the clinical records and the status of each patient was checked using the Social Security Index, a governmental mortality search engine based on Social Security number; however, this tool does not provide the cause of death. Treatment success was judged according to criteria based on the Delphi international multidisciplinary consensus: infection eradication characterized by a healed wound without drainage, fistula, or pain and no infection recurrence; no occurrence of periprosthetic joint infection-related mortality (e.g., sepsis, necrotizing fasciitis); and no subsequent surgical intervention for infection after reimplantation surgery ${ }^{14}$. Given that the Delphi criteria do not account for patients who do not undergo the reimplantation phase of the two-stage exchange, treatment success also included no subsequent surgical intervention for infection after spacer implantation in patients with a retained spacer and no mortality related to the infection.

\section{Statistical Analysis}

Differences in the reimplantation rate between gram-negative and grampositive organisms and between resistant and susceptible organisms were calculated with use of the Fisher exact test. A logistic regression was used to assess the correlation between the Charlson Comorbidity Index and the reimplantation rate. The number of surgeries and spacers were analyzed with use of the Wilcoxon test for binary comparison. The total number of surgeries was compared with the patient's comorbidities, including ASA score, Charlson Comorbidity Index, and body mass index. Significance was set at $\mathrm{p}<0.05$.

\section{Source of Funding}

There was no external funding source for this study.

\section{Results}

R eimplantation occurred in 417 (82.7\%) of 504 cases. The Rmean duration from resection arthroplasty to reimplantation was 4.2 months (median, 2.7 months [range, 0.7 to 131.7 months]) (Table II). The mean follow-up duration after spacer insertion was 57.4 months for patients who underwent reimplantation and 42.7 months for those who did not undergo reimplantation. Sixty (11.9\%) of 504 cases required a mean of 1.1 spacer exchanges (range, one to six spacer exchanges) in the interstage period between initial resection arthroplasty and eventual 
The Journal of Bone \& Joint Surgery $\cdot$ JbJs.org Volume $97-A \cdot$ Number $18 \cdot$ September 16,2015
The Fate of Spacers in the Treatment of Periprosthetic JOINT INFECTION

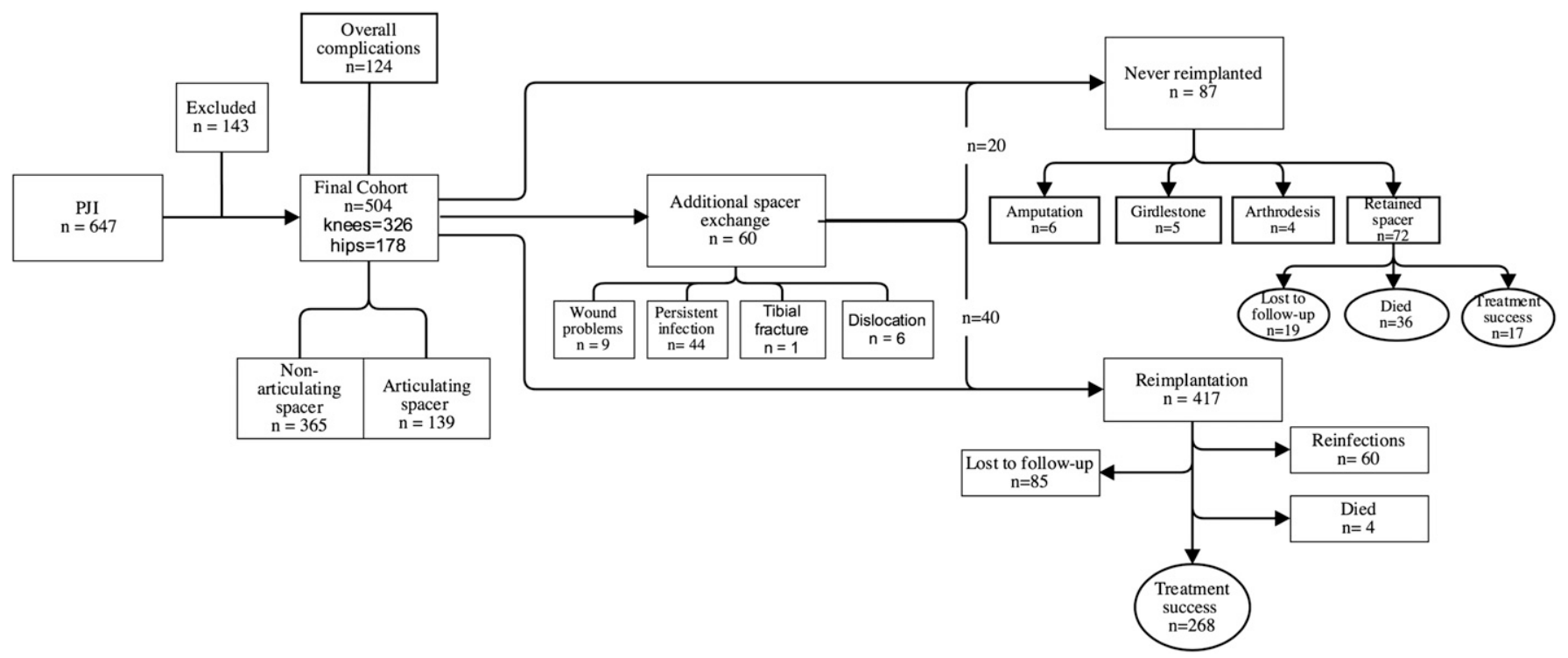

Fig. 1

Flowchart depicting the outcomes of the final cohort. PJI = periprosthetic joint infection.

reimplantation (Fig. 1). The reasons for requiring additional spacer exchanges included persistent infection (forty-four cases [73.3\%]), spacer dislocation (six cases [10\%]), wound-related problems (nine cases $[15 \%]$ ), and fracture of the tibia (one case $[1.7 \%])$. The reimplantation rate was $87.1 \%$ for articulating spacers and $81.2 \%$ for static spacers, and the duration to reimplantation was 4.3 months for articulating spacers and 4.0 months for static spacers. There was no difference in the reimplantation rate $(\mathrm{p}=0.146)$ or treatment success rate $(\mathrm{p}=0.730)$ between the types of spacers.

Of the cases undergoing reimplantation, 329 joints (78.9\%) had a minimum one-year follow-up. Treatment success was $81.4 \%$ for the entire cohort, $81.4 \%$ for knees, and $81.7 \%$ for hips (Fig. 2). Following reimplantation, the mean follow-up duration was 57.0 months in cases with treatment success and 50.4 months in cases with failure. The mean number of surgeries between the resection arthroplasty with spacer insertion and the reimplantation was 1.3 surgeries (range, one to six surgeries), which included additional spacer exchanges, irrigation and debridement, and reoperation for wound-related complications. Of those eightyseven cases that did not undergo second-stage reimplantation, six required amputation (6.9\%), five (5.7\%) underwent a Girdlestone procedure, four $(4.6 \%)$ underwent arthrodesis, and seventy-two $(82.8 \%)$ retained the spacer. Of the seventy-two cases that retained the spacer, treatment success was $23.6 \%$ (seventeen cases) at a minimum one-year follow-up (Fig. 1).

Of the seventy-two cases of retained spacers, nineteen (26.4\%) were lost to follow-up after the decision was made to use the retained spacer as the definitive treatment, leaving fifty-three cases. When excluding cases lost to follow-up, treatment success was $32.1 \%$ (seventeen cases). In thirty-six cases $(50.0 \%)$ with retained spacers, the patients died before the second stage at a mean time of 38.3 months (range, 0.4 to 127.5 months), with five of those deaths occurring during the initial hospitalization for spacer in- sertion; we confirmed that mortality in the latter five cases was related to the infection. The major reasons for a retained spacer among the seventy-two cases were no desire for reimplantation (2.8\% [two cases]) or being unfit for the surgical procedure $(20.8 \%$ [fifteen cases]) for a variety of reasons (e.g., severe bone loss and non-healing ulcers).

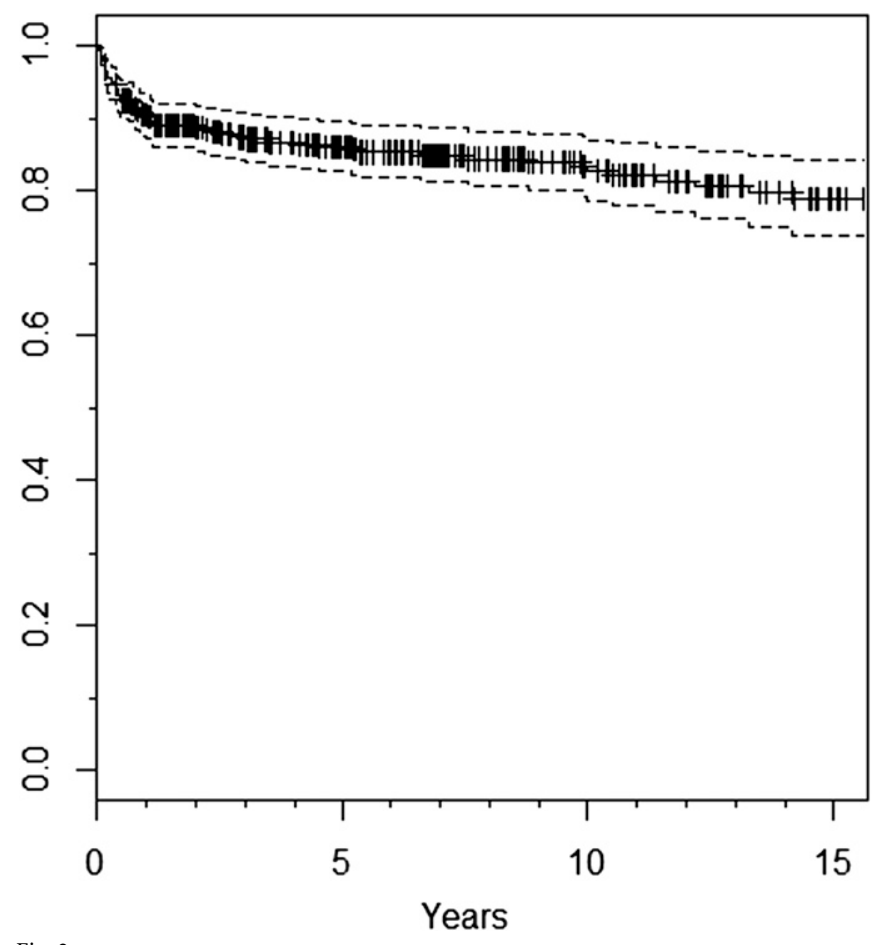

Fig. 2

Kaplan-Meier survivorship curve with treatment failure as an end point. The dashed lines indicate the $95 \%$ confidence interval. 
The Journal of Bone \& Joint Surgery · Jbjs.org Volume 97-A - Number $18 \cdot$ September 16,2015
The Fate of Spacers in the Treatment of Periprosthetic JOINT INFECTION
The overall incidence of mortality for the cohort was 1.2\% (six cases) within thirty days, $2.6 \%$ (thirteen cases) within ninety days, $6.5 \%$ (thirty-three cases) within one year, and $10.3 \%$ (fiftytwo cases) within two years. In comparison, the death rate of patients who are sixty-five to seventy-four years of age in the United States is $2.0 \%{ }^{15}$. The most common infecting organisms at the time of resection arthroplasty and spacer insertion were coagulase-negative Staphylococcus (16.7\%) and methicillinsensitive Staphylococcus aureus (14.5\%) (Table III). For patients with reinfection, $22.5 \%$ were infected with the same organism as that identified at the time of initial resection arthroplasty. A significantly increased number of interim spacer exchanges were performed in the seventy-six patients who had periprosthetic joint infection by a resistant $\operatorname{organism}(\mathrm{s})(\mathrm{p}=0.02)$, but no difference in reimplantation rate was observed (Table IV). In addition, patients with gram-negative bacteria demonstrated a lower reimplantation rate than those infected with gram-positive bacteria $(\mathrm{p}=0.002)$.

When stratified by comorbidities, increased Charlson Comorbidity Index $(p<0.0001)$ and presence of rheumatoid arthritis $(\mathrm{p}=0.03)$ were associated with a lower reimplantation rate (Table IV). Furthermore, the total number of procedures was significantly higher when associated with higher body mass index $(\mathrm{p}=0.006)$.

\section{Discussion}

$\mathrm{T}$ he success of two-stage exchange arthroplasty for the treatment of chronic periprosthetic joint infection has been reported to approach or to exceed $80 \%$ in the majority of studies ${ }^{16-22}$. However, there is a widespread heterogeneity on the reporting of the clinical outcomes of two-stage exchange arthroplasty. The most important fact is that the definition of success has varied in these reports. The lack of consensus with regard to what constitutes a successful treatment outcome for periprosthetic joint infection makes it difficult to compare the outcomes between studies and ultimately between different treatment strategies. This has led to the development of a multidisciplinary consensus to better define success ${ }^{14}$. However, despite the availability of an acceptable definition for success, it is not known whether success should take into account patients who had a failure after the firststage surgical procedure and never underwent reimplantation for a variety of reasons.

The majority of studies showing the outcome of two-stage exchange arthroplasty do not take into account the attrition that occurs between the two stages and arguably overestimate the success of this surgical procedure. Although there are a variety of reasons for the attrition between stages, one sobering recognition is that the proportion of patients who die after the initial resection arthroplasty is not small ${ }^{1,23}$.

This study, specifically designed to evaluate the clinical course of patients in between two stages, demonstrated that almost one-fifth of patients who underwent resection arthroplasty and spacer insertion did not undergo a subsequent reimplantation. Within the literature, there is considerable variation in the reimplantation rates following explantation, ranging from $28.6 \%{ }^{24}$ to $100 \%^{25-29}$, and most studies have demonstrated reimplantation rates above $80 \% \%^{1,2,530-34}$. Failure to reimplant may occur for a variety of reasons, including mortality, medical comorbidity, patients lost to follow-up, patients satisfied with their current level of function in the setting of a retained spacer ${ }^{19}$, and persistent infection that may ultimately result in definitive treatment with amputation, arthrodesis, or lifetime antibiotic suppression. Therefore, the reimplantation rates within the literature and in the present study suggest that the number of patients who fail to undergo reimplantation is not inconsequential and that reported outcomes following completion of the second stage neglect the nearly $20 \%$ of treatment failures in the interstage period.

We suggest that the success of two-stage treatment be considered from the point of initial spacer implantation rather than following reimplantation to account for failures that occur in the interstage period. For example, Berend et al. reported a success rate of $83 \%$ following reimplantation in a study of 205 hips. However, when accounting for a reimplantation rate of $92 \%$, the rate of infection control following initial spacer implantation dropped to $77 \%{ }^{1}$. Another study of 130 patients with periprosthetic joint infection demonstrated a $95 \%$ rate of eradication following reimplantation, but only a $68 \%$ rate when taking into account a reimplantation rate of $84.6 \%$ and those who either had been lost to follow-up or had died ${ }^{28}$. Despite having a lower reimplantation rate, the first stage as a starting point better represents the actual clinical course and explains the seemingly low infection eradication rates reported in the current study and previous reports from our institution $^{35-38}$.

It is also important to point out that, even for patients in the present study who ultimately underwent reimplantation, many underwent spacer exchange or surgical intervention for wound-related problems in the interstage period, with all of the inherent risks of added surgical procedures ${ }^{19,39,40}$. In nearly one of five patients, the intended two-stage exchange never occurred, with patients requiring arthrodesis or amputation or resorting to living with the implanted spacers. When taking into account the failures that occurred in the interstage period in addition to the patients who were reinfected after reimplantation, it becomes clear that the failure rate in the interstage period approaches the reinfection rate that is usually seen with the two-stage exchange, at around $17 \%$.

Although several studies have investigated the impact of organism type and resistance profile on the eventual outcome of two-stage exchange arthroplasty, we are unaware of any studies investigating the role of microorganisms in the interstage period. We noted that patients with periprosthetic joint infection caused by resistant organisms and gram-negative organisms had a more complicated course requiring additional surgeries, and fewer of these patients underwent subsequent reimplantation (Table IV). The latter may relate to the fact that surgical management of patients with periprosthetic joint infection caused by more virulent organisms is more challenging ${ }^{32,36,41,42}$. This is an important finding because patients with a culture-negative infection or resistant organisms are typically managed by two-stage exchange; however, our study demonstrates that these infections are still associated with a reduced reimplantation rate. In addition to the type of infecting organism, the overall medical comorbidity of the 
The Journal of Bone \& Joint Surgery · Jbjs.org Volume 97-A · Number $18 \cdot$ September 16, 2015
The Fate of Spacers in the Treatment of Periprosthetic JOINT INFECTION patients also influenced the reimplantation rate and number of surgical procedures in the interstage period, with sicker patients having a more protracted interstage course. Surgeons should be aware that these factors, the type of infecting organism and comorbid medical conditions, might influence the likelihood of a patient completing both stages of a two-stage exchange.

There were limitations to the current study. The retrospective nature of the study, with all of the inherent limitations of such a study design, may have allowed for the introduction of bias. In addition, the current study intentionally did not include evaluation of radiographic or functional outcomes, which may be seen as a potential weakness. Furthermore, despite all our efforts, including calling all patients as part of another study, some patients were lost to follow-up or did not have long-term follow-up. However, all patients were included regardless of the follow-up to prevent an overestimation of the results and to allow a more realistic picture of the actual clinical course. In addition, some may argue that reinfection by a different organism than the initial infection, which happened in the majority (77.5\%) of the cases of reinfection, should not be attributed to failure of the initial treatment. However, it is possible that the organisms cultured at the time of failure were in fact present at the time of the initial periprosthetic joint infection but were not captured by the culture technique, rather than representing a new infection. Because the latter possibility cannot be ruled out, we believe that an infection with a different organism may still be attributed to failure of the initial two-stage exchange. In addition, subsequent surgical procedure for infection and mortality were used to evaluate treatment success, and these do not require a recurrent organism to be present according to the Delphi consensus criteria ${ }^{14}$. Additionally, infection-related mortality was difficult to confirm in deaths that occurred outside of a hospital. Although the date of death was known in these patients, the precise cause of death could not be determined. Lastly, it should be noted that there was not a clear reimplantation protocol and that some failures may potentially have been caused by variations in the reimplantation protocol, for example, returning to the operating room too soon or differences in an antibiotic-free period. This inconsistency can be attributed to the several surgeons involved in this study and the lack of current guidelines and literature for determining the optimal time for reimplantation.

Despite the aforementioned limitations, this study highlights the fact that the commonly held belief that two-stage exchange arthroplasty carries a high success rate for eradication of periprosthetic joint infection may need to be reexamined. A considerable number of patients undergoing resection arthroplasty and spacer insertion do not undergo subsequent reimplantation for a variety of reasons, and many are subjected to interim surgical procedures. Of those who undergo reimplantation, nearly one-fifth experience a failure later because of persistence of infection or reinfection. The future management of patients with periprosthetic joint infection needs to change as current strategies, which have a high burden on the patient and society, are far from perfect.

Miguel M. Gomez, MD

Timothy L. Tan, MD

Jorge Manrique, MD

Gregory K. Deirmengian, MD

Javad Parvizi, MD, FRCS

Rothman Institute at Thomas Jefferson University,

125 South 9th Street, Suite 1000,

Philadelphia, PA 19107.

E-mail address for J. Parvizi: research@rothmaninstitute.com

\section{References}

1. Berend KR, Lombardi AV Jr, Morris MJ, Bergeson AG, Adams JB, Sneller MA. Two-stage treatment of hip periprosthetic joint infection is associated with a high rate of infection control but high mortality. Clin Orthop Relat Res. 2013 Feb;471 (2):510-8

2. Lim SJ, Park JC, Moon YW, Park YS. Treatment of periprosthetic hip infection caused by resistant microorganisms using 2-stage reimplantation protocol. J Arthroplasty. 2009 Dec;24(8):1264-9. Epub 2009 Jun 12.

3. Hsieh PH, Shih $\mathrm{CH}$, Chang YH, Lee MS, Shih HN, Yang WE. Two-stage revision hip arthroplasty for infection: comparison between the interim use of antibiotic-loaded cement beads and a spacer prosthesis. J Bone Joint Surg Am. 2004 Sep;86 (9):1989-97.

4. Volin SJ, Hinrichs SH, Garvin KL. Two-stage reimplantation of total joint infections: a comparison of resistant and non-resistant organisms. Clin Orthop Relat Res. 2004 Oct;427:94-100.

5. Yamamoto K, Miyagawa N, Masaoka T, Katori Y, Shishido T, Imakiire A. Clinical effectiveness of antibiotic-impregnated cement spacers for the treatment of infected implants of the hip joint. J Orthop Sci. 2003;8(6):823-8.

6. Puhto AP, Puhto TM, Niinimäki TT, Leppilahti J, Syrjälä HP. Two-stage revision for prosthetic joint infection: outcome and role of reimplantation microbiology in 107 cases. J Arthroplasty. 2014 Jun;29(6):1101-4. Epub 2013 Dec 25.

7. Macheras GA, Kateros K, Galanakos SP, Koutsostathis SD, Kontou E, Papadakis SA. The long-term results of a two-stage protocol for revision of an infected total knee replacement. J Bone Joint Surg Br. 2011 Nov;93(11):1487-92.

8. Mahmud T, Lyons MC, Naudie DD, Macdonald SJ, McCalden RW. Assessing the gold standard: a review of 253 two-stage revisions for infected TKA. Clin Orthop Relat Res. 2012 Oct;470(10):2730-6.

9. Brunnekreef J, Hannink G, Malefijt MdeW. Recovery of knee mobility after a static or mobile spacer in total knee infection. Acta Orthop Belg. 2013 Feb;79 (1):83-9.
10. Chiang ER, Su YP, Chen TH, Chiu FY, Chen WM. Comparison of articulating and static spacers regarding infection with resistant organisms in total knee arthroplasty. Acta Orthop. 2011 Aug;82(4):460-4.

11. Pattyn $C$, De Geest $T$, Ackerman $P$, Audenaert E. Preformed gentamicin spacers in two-stage revision hip arthroplasty: functional results and complications. Int Orthop. 2011 Oct;35(10):1471-6. Epub 2010 Nov 30.

12. Owens WD, Felts JA, Spitznagel EL Jr. ASA physical status classifications: a study of consistency of ratings. Anesthesiology. 1978;49:239-43.

13. Charlson ME, Pompei $P$, Ales KL, MacKenzie CR. A new method of classifying prognostic comorbidity in longitudinal studies: development and validation. J Chronic Dis. 1987;40(5):373-83.

14. Diaz-Ledezma C, Higuera CA, Parvizi J. Success after treatment of periprosthetic joint infection: a Delphi-based international multidisciplinary consensus. Clin Orthop Relat Res. 2013 Jul;471(7):2374-82. Epub 2013 Feb 26.

15. National Center for Health Statistics, National Vital Statistics System. Death rates by 10-year age groups: United States and Each State, 1997-2007. 2012 Feb 10. http://www.cdc.gov/nchs/nvss/mortality/gmwk23r.htm. Accessed 2015 May 26.

16. Silvestre A, Almeida F, Renovell P, Morante E, López R. Revision of infected total knee arthroplasty: two-stage reimplantation using an antibiotic-impregnated static spacer. Clin Orthop Surg. 2013 Sep;5(3):180-7. Epub 2013 Aug 20.

17. Berbari EF, Marculescu C, Sia I, Lahr BD, Hanssen AD, Steckelberg JM, Gullerud $\mathrm{R}$, Osmon DR. Culture-negative prosthetic joint infection. Clin Infect Dis. $2007 \mathrm{Nov}$ 1;45(9):1113-9. Epub 2007 Sep 26.

18. Castelli CC, Gotti V, Ferrari R. Two-stage treatment of infected total knee arthroplasty: two to thirteen year experience using an articulating preformed spacer. Int Orthop. 2014 Feb;38(2):405-12. Epub 2014 Jan 26.

19. Choi HR, Freiberg AA, Malchau H, Rubash HE, Kwon YM. The fate of unplanned retention of prosthetic articulating spacers for infected total hip and total knee arthroplasty. J Arthroplasty. 2014 Apr;29(4):690-3. Epub 2013 Aug 6. 
The Journal of Bone \& Joint Surgery $\cdot$ JBjS. Org Volume 97-A - Number $18 \cdot$ September 16,2015
The Fate of Spacers in the Treatment of Periprosthetic JOINT INFECTION
20. Gooding CR, Masri BA, Duncan CP, Greidanus NV, Garbuz DS. Durable infection control and function with the PROSTALAC spacer in two-stage revision for infected knee arthroplasty. Clin Orthop Relat Res. 2011 Apr;469(4):985-93.

21. Kaminski $A$, Citak $M$, Schildhauer $T A$, Fehmer T. Success rates for initial eradication of peri-prosthetic knee infection treated with a two-stage procedure. Ortop Traumatol Rehabil. 2014 Jan-Feb;16(1):11-6.

22. Stockley I, Mockford BJ, Hoad-Reddick A, Norman P. The use of two-stage exchange arthroplasty with depot antibiotics in the absence of long-term antibiotic therapy in infected total hip replacement. J Bone Joint Surg Br. 2008 Feb;90(2): 145-8.

23. Zmistowski B, Karam JA, Durinka JB, Casper DS, Panvizi J. Periprosthetic joint infection increases the risk of one-year mortality. J Bone Joint Surg Am. 2013 Dec 18;95(24):2177-84.

24. Scharfenberger A, Clark M, Lavoie G, O'Connor G, Masson E, Beaupre LA. Treatment of an infected total hip replacement with the PROSTALAC system. Part 1: infection resolution. Can J Surg. 2007 Feb;50(1):24-8.

25. Evans RP. Successful treatment of total hip and knee infection with articulating antibiotic components: a modified treatment method. Clin Orthop Relat Res. 2004 Oct:427:37-46.

26. Nusem I, Morgan DA. Structural allografts for bone stock reconstruction in twostage revision for infected total hip arthroplasty: good outcome in 16 of 18 patients followed for 5-14 years. Acta Orthop. 2006 Feb;77(1):92-7.

27. Romanò $C L$, Romanò $D$, Logoluso N, Meani E. Long-stem versus short-stem preformed antibiotic-loaded cement spacers for two-stage revision of infected total hip arthroplasty. Hip Int. 2010 Jan-Mar;20(1):26-33.

28. Toulson C, Walcott-Sapp S, Hur J, Salvati E, Bostrom M, Brause B, Westrich GH. Treatment of infected total hip arthroplasty with a 2-stage reimplantation protocol: update on “our institution's" experience from 1989 to 2003. J Arthroplasty. 2009 Oct:24(7):1051-60. Epub 2008 Oct 9.

29. Whittaker JP, Warren RE, Jones RS, Gregson PA. Is prolonged systemic antibiotic treatment essential in two-stage revision hip replacement for chronic grampositive infection? J Bone Joint Surg Br. 2009 Jan;91(1):44-51.

30. Hofmann AA, Goldberg TD, Tanner AM, Cook TM. Ten-year experience using an articulating antibiotic cement hip spacer for the treatment of chronically infected total hip. J Arthroplasty. 2005 Oct;20(7):874-9.
31. Incavo SJ, Russell RD, Mathis $\mathrm{KB}$, Adams $\mathrm{H}$. Initial results of managing severe bone loss in infected total joint arthroplasty using customized articulating spacers. J Arthroplasty. 2009 Jun;24(4):607-13. Epub 2008 Jul 9.

32. Leung F, Richards CJ, Garbuz DS, Masri BA, Duncan CP. Two-stage total hip arthroplasty: how often does it control methicillin-resistant infection? Clin Orthop Relat Res. 2011 Apr;469(4):1009-15.

33. Magnan B, Regis D, Biscaglia R, Bartolozzi P. Preformed acrylic bone cement spacer loaded with antibiotics: use of two-stage procedure in 10 patients because of infected hips after total replacement. Acta Orthop Scand. 2001 Dec;72(6):591-4. 34. Younger AS, Duncan CP, Masri BA, McGraw RW. The outcome of two-stage arthroplasty using a custom-made interval spacer to treat the infected hip. J Arthroplasty. 1997 Sep;12(6):615-23.

35. Huang R, Hu CC, Adeli B, Mortazavi J, Parvizi J. Culture-negative periprosthetic joint infection does not preclude infection control. Clin Orthop Relat Res. 2012 Oct;470(10):2717-23.

36. Parvizi J, Azzam K, Ghanem E, Austin MS, Rothman RH. Periprosthetic infection due to resistant staphylococci: serious problems on the horizon. Clin Orthop Relat Res. 2009 Jul;467(7):1732-9. Epub 2009 May 1.

37. Sherrell JC, Fehring TK, Odum S, Hansen E, Zmistowski B, Dennos A, Kalore N Periprosthetic Infection Consortium. The Chitranjan Ranawat Award: fate of twostage reimplantation after failed irrigation and débridement for periprosthetic knee infection. Clin Orthop Relat Res. 2011 Jan;469(1):18-25.

38. Zmistowski B, Fedorka CJ, Sheehan E, Deirmengian G, Austin MS, Parvizi J. Prosthetic joint infection caused by gram-negative organisms. J Arthroplasty. 2011 Sep;26(6)(Suppl):104-8. Epub 2011 Jun 8.

39. Jung J, Schmid NV, Kelm J, Schmitt E, Anagnostakos K. Complications after spacer implantation in the treatment of hip joint infections. Int J Med Sci. 2009;6 (5):265-73. Epub 2009 Sep 2

40. Struelens B, Claes $S$, Bellemans J. Spacer-related problems in two-stage revision knee arthroplasty. Acta Orthop Belg. 2013 Aug;79(4):422-6.

41. Hirakawa K, Stulberg BN, Wilde AH, Bauer TW, Secic M. Results of 2-stage reimplantation for infected total knee arthroplasty. J Arthroplasty. 1998 Jan;13(1):22-8. 42. Kurd MF, Ghanem E, Steinbrecher J, Parvizi J. Two-stage exchange knee arthroplasty: does resistance of the infecting organism influence the outcome? Clin Orthop Relat Res. 2010 Aug;468(8):2060-6. 